\title{
Distribution of Porcine Haemal Nodes and Morphological Variations in the Haemal Nodes of Cattle and West African Dwarf Goats
}

\author{
Anietie Francis UDOUMOH*, Daniel Nwagbo EZEASOR, \\ Udensi Maduabuchi IGWEBUIKE
}

\author{
University of Nigeria,Nsukka,Nigeria; anietie.udoumoh@unn.edu.ng (*orrespondingauthor); daniel.ezeasor@unn.edu.ng; \\ udensi.igwebuike@unn.edu.ng
}

\begin{abstract}
Apparently healthy, non-lactating, non-gravid adult large white pigs (15), adult cattle (10) and adult West African Dwarf (WAD) goats of either genders were used to investigate the morphology of haemal nodes using gross anatomical and histological techniques. The results demonstrated that the haemal nodes of pigs occurred in the thoracic, abdominal and pelvic regions along the course of blood vessels. The ranges of the longest diameters of the dark brown organs were $6.1-30.3 \mathrm{~cm}$ in pigs, $4.1-18.7 \mathrm{~cm}$ in cattle and $2.7-8.2 \mathrm{~cm}$ in WAD goats. Bovine haemal nodes showed cortical and medullary parenchymal areas, with the cortex demonstrating primary and secondary lymphoid follicles in a circumferential fashion. The medulla showed blood filled medullary sinusoids and medullary cords. In WAD goat, the reticular cells and smooth muscle cells of the capsule were oriented in different directions and the subcapsular, cortical and medullary sinusoids exhibited erythrocytes in pockets. In conclusion, the present study has provided information on the distribution of haemal nodes in pigs as well as other unique morphological features of cattle and WAD goat haemal nodes that could aid their identification and suggest their roles in the body.
\end{abstract}

Keywords: cattle, distribution, haemal nodes, morphology, pigs, WAD goats

\section{Introduction}

In all animal species, organs of the body are strategically distributed to facilitate their functions. The distribution of lymphoid organs which has been studied extensively shows that their anatomic locations and structural designs are related to their functions. In ruminants, haemal node is widely studied and shown to be distributed along the blood vascular system. They are reported in the sub-lumbar area along the vena cava, thoracic and abdominal aorta, subcutaneous region of the head and mesenteric region along small blood vessels (Bacha and Bacha, 2000; Casteleyn et al., 2008). Although their functional significance is yet to be elucidated, several reports provide evidence that haemal node is involved in blood storage, erythrophagocytosis, erythopoiesis, platelet formation and immune functions (Ezeasor et al., 1989; Cerutti and Guerrero, 2001; Cerutti and Guerrero, 2008). The frequency of the occurrence of haemal nodes in the ruminant species as reported by several authors could suggest the clinical relevance of the organ, particularly in disease prevention and diagnosis; thus it is important to provide baseline information on haemal nodes of pigs, cattle and goats with their specific histological features. Although several authors doubt the occurrence of haemal nodes in the pigs, recent report on the histological features of porcine haemal nodes shows the presence of haemal nodes in this species (Udoumoh and Ezeasor, 2015).
Furthermore, the most common histological feature of haemal node as reported in all species is the concentration of red blood cells in the sinusoids (Ezeasor and Singh, 1988; Udoumoh and Ezeasor, 2015). However, some authors believed that considerable interspecies and intra-species variations in the structure of haemal nodes could occur (Winqvist, 1954; Ezeasor and Singh, 1988; Ozaydin et al., 2012). Available information on the haemal node of pigs were based on their histological features (Udoumoh and Ezeasor, 2015) without reference to their definite anatomical locations while information on the macro and microscopic features of haemal nodes in cattle (Bassan et al., 1999; Casteleyn et al., 2008; Cerutti and Guerrero, 2008) and goats (Ezeasor and Singh, 1988; Choudhary et al., 2011; Ozaydin et al., 2012) were based on the general features of haemal nodes without emphasis on the species variations; even more, there is paucity of information on the basic gross anatomical features of haemal nodes in these species.

Therefore, the present study will concentrate on the gross and histomorphological features of haemal nodes in pigs, cattle, and WAD goats with emphasis on some basic gross anatomical features, distribution of porcine haemal nodes, comparative structural features and the functional peculiarities of the organ that may assist in disease diagnosis and in the understanding of their roles in disease conditions. 


\section{Materials and Methods}

\section{Experimental animals}

Fifteen large white pigs ( 2 - 3 years), 10 adult cattle (2 - 4 years) and 10 adult West African Dwarf (WAD) goats (2 4years) of both sexes were used for this study. The animals were non-gravid, non-lactating, apparently healthy animals. Five of the large white pigs were obtained separately from local markets in Nsukka local government Area, Enugu State, Nigeria, for the study of the distribution of porcine haemal nodes and sacrificed for human consumption, while the remaining 10 animals of each species used for the study of other gross and histological features were abattoir animals sacrificed for human consumption in Nsukka local government abattoir, Enugu State, Nigeria.

\section{Distribution of porcine haemal nodes}

Following slaughter, the subcutaneous regions of the head and neck, the thoracic organs and cavity, the abdominal viscerals and cavity, the inguinal region, and regions of the superficial lymph nodes were examined for the presence, number and consistency of haemal nodes. Haemal node samples were obtained for histological investigations. Photographs were captured with a Sony 14.1 mega pixel digital camera.

\section{Gross anatomical techniques}

Following slaughter, the colors, shapes and sizes of haemal nodes were studied. The average sizes of the nodes were determined for each species by measuring the widest diameters of 20 haemal nodes and dividing the sum of these diameters by 20.

\section{Histological techniques}

Specimens of cattle and WAD goat haemal nodes were cut and fixed by immersion in Bouin's fluid for $48 \mathrm{hrs}$. These were later dehydrated in increasing concentrations of ethanol, cleared in three changes of xylene, and embedded in paraffin wax. Tissue sections of about $5 \mu \mathrm{m}$ thick were obtained using a rotary microtome. These sections were mounted on microscope slides and stained routinely with haematoxylin and eosin for light microscopy. Photomicrographs were captured using a Moticam Images Plus 2.0 digital camera (Motic Group Ltd) attached to the Motic binocular light microscope.

\section{Results}

\section{Distribution of porcine haemal nodes}

Haemal nodes of pigs were distributed in the thoracic, abdominal and pelvic regions of the body (Table 1). They were present singly along the course of the blood vascular tracts in these regions (Fig. 1). In the thoracic region, haemal nodes were frequently observed along the course of the thoracic aorta near the aortic lymph nodes, whereas, in the abdominal region, most of the haemal nodes were observed in the abdominal cavity. In most of the animals, they were seen in the peri-renal areas receiving little branches of vessels from the renal vessels and occasionally along paths of small vessels from the caudal mesenteric artery. Porcine haemal nodes were also occasionally seen along the hepatic portal vein and were drained by tiny branches from the vein. Haemal nodes observed in the pelvic region were frequently seen at the junction of the external iliac and internal iliac vessels. About 1 - 3; 3 - 7; and 2 - 3 haemal nodes were observed in the thoracic, abdominal and pelvic regions respectively (Figs. 1,2).

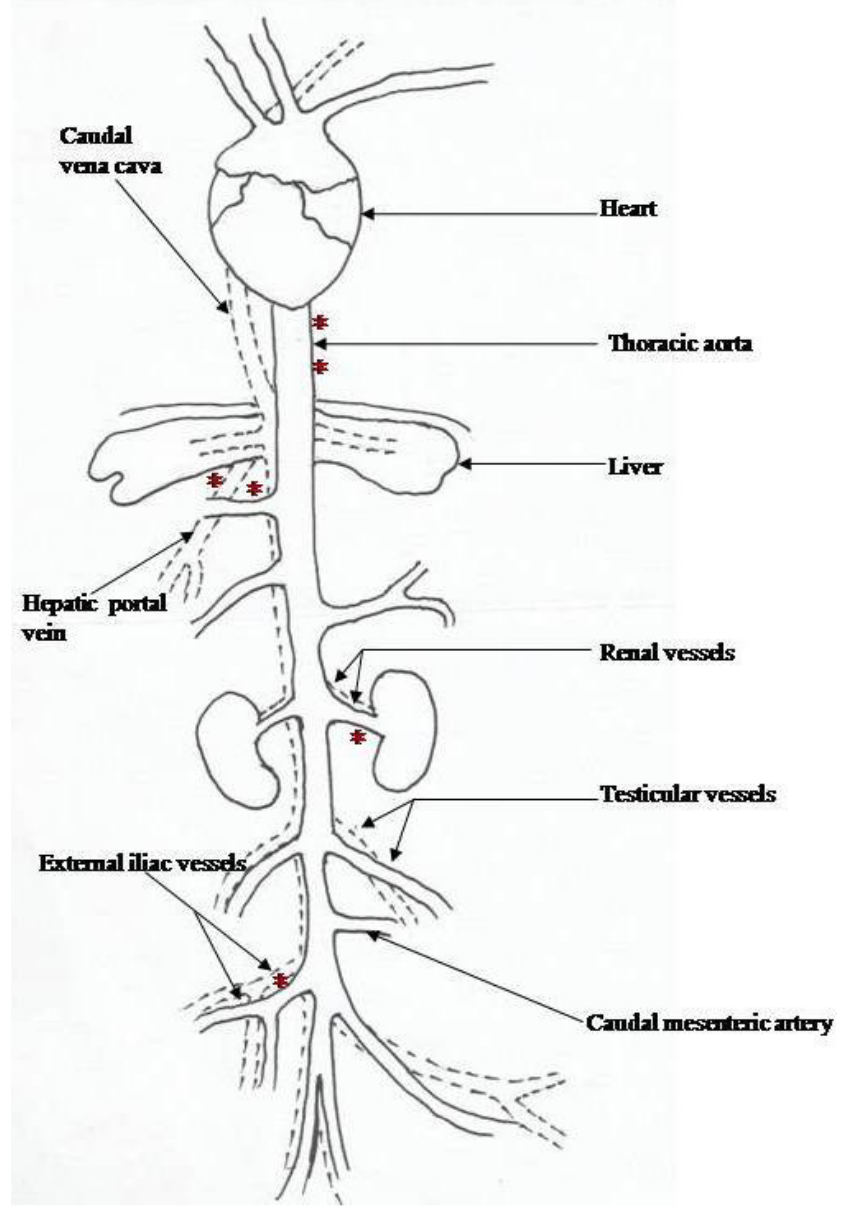

Fig. 1. Schematic diagram showing the distribution of haemal nodes (asterisk) along the blood vessels of pigs

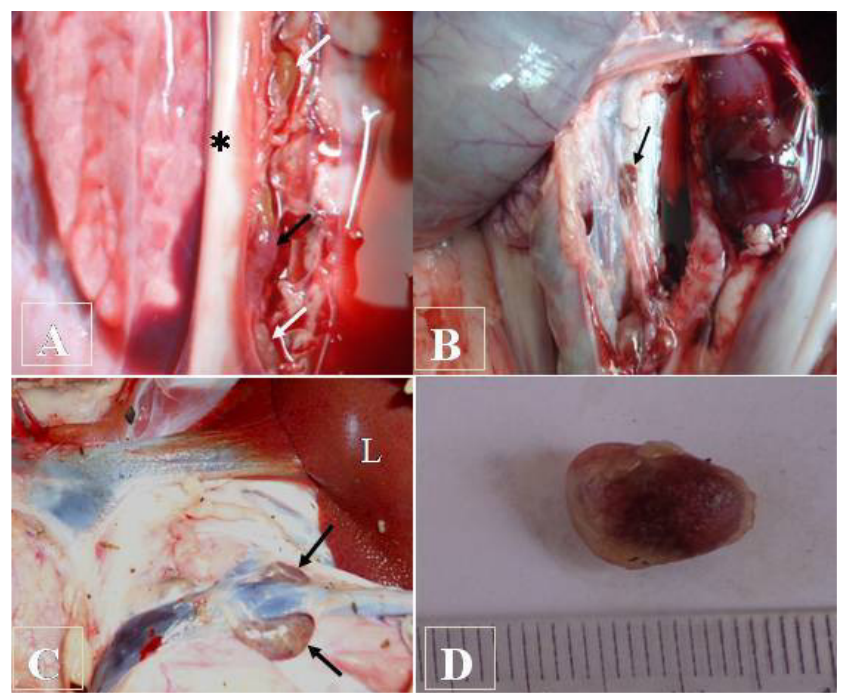

Fig. 2. Photograph of thoracic cavity (A) and abdominal cavity (B, C) of pig showing haemal node (black arrows), thoracic aorta (black asterisk), aortic lymph nodes (white arrow), kidney (white asterisk) and liver. Note the porcine haemal node (D) 
424

Table 1. Regional distribution of porcine haemal nodes

\begin{tabular}{|c|c|c|c|c|}
\hline S/No & Region & specific anatomic locations & Number & Consistency \\
\hline 1 & Head & - & 0 & - \\
\hline 2 & Neck & - & 0 & - \\
\hline 3 & Thoracic & Along the thoracic aorta, near aortic lymph nodes & $1-3$ & Consistent \\
\hline \multirow{3}{*}{4} & \multirow{3}{*}{ Abdominal } & $\begin{array}{l}\text { Along paths of small blood vessels in the peri- } \\
\text { renal areas }\end{array}$ & $2-3$ & Consistent \\
\hline & & $\begin{array}{c}\text { Along paths of small blood vessels from the caudal } \\
\text { mesenteric artery }\end{array}$ & $1-2$ & Occasional \\
\hline & & Along the hepatic portal vein & $0-2$ & Seen in one pig only \\
\hline 5 & Pelvic & Along the external and internal iliac vessels & $2-3$ & Consistent \\
\hline
\end{tabular}

Table 2. Average length and breadth of the haemal nodes of adult pig, cattle and WAD goat $(\mathrm{cm})$

\begin{tabular}{cccc}
\hline & Pig & Cattle & Goat \\
\hline Length & $1.72 \pm 0.15$ & $1.02 \pm 0.09$ & $0.47 \pm 0.03$ \\
Breadth & $0.97 \pm 0.06$ & $0.80 \pm 0.07$ & $0.35 \pm 0.02$ \\
\hline
\end{tabular}

Table 3. Range of the length and breadth of haemal nodes $(\mathrm{mm})$

\begin{tabular}{ccc}
\hline Species & Range of length & Range of breadth \\
\hline Pig & $6.1-30.3$ & $3.5-15.2$ \\
Cattle & $4.1-18.7$ & $3.2-15.4$ \\
WAD goat & $2.7-8.2$ & $1.9-5.7$ \\
\hline
\end{tabular}

\section{Gross anatomy of porcine haemal node}

Grossly, the porcine haemal nodes varied greatly in shape. Their shape ranged from spherical to kidney-shaped organs with oval to round outlines. These pink or dark brown organs varied widely in size ranging from $0.61 \mathrm{~cm}$ to $3.03 \mathrm{~cm}$ in length and $0.35 \mathrm{~cm}$ to $1.52 \mathrm{~cm}$ in breadth. The determined mean size of 20 porcine haemal nodes studied was $1.72 \pm 0.15 \mathrm{~cm}$ in length and $0.97 \pm 0.06 \mathrm{~cm}$ in breadth (Table 2). The range of the length of porcine haemal nodes was $6.1-30.3 \mathrm{~cm}$ (Table 3). With the aid of a stereomicroscope, porcine haemal nodes demonstrated thin and glittering capsules which contained longitudinal grooves (Fig.3).

\section{Bovine haemal node}

The bovine haemal nodes were dark-brown organs which appeared round to oval in outline and spherical to kidney-shaped. These nodes varied widely in size ranging from $0.41 \mathrm{~cm}$ to $1.87 \mathrm{~cm}$ in length and $0.32 \mathrm{~cm}$ to $1.54 \mathrm{~cm}$ in breadth. The determined mean size of the 20 bovine haemal nodes studied was $1.02 \pm 0.09 \mathrm{~cm}$ in length and 0.80 $\pm 0.07 \mathrm{~cm}$ in breadth (Table 2). The range of the length of bovine haemal node was $4.1-18.7 \mathrm{~cm}$ (Table 3).

\section{West African Dwarf(WAD) goat haemal nodes}

The WAD goat haemal nodes were small, brown to dark-brown organs with oval to round outlines and spherical to kidney-shaped. These haemal nodes varied greatly in size and ranged from 0.27 to $0.82 \mathrm{~cm}$ in length and between 0.19 to $0.57 \mathrm{~cm}$ in breadth. The determined mean size of WAD goat haemal nodes studied was $0.47 \pm$ $0.03 \mathrm{~cm}$ in length and $0.35 \pm 0.02 \mathrm{~cm}$ in breadth (Table 2).

\section{Histology of cattle haemal node}

Bovine haemal nodes are encapsulated organs which contained cortical and medullary parenchymal areas. The capsule exhibited two layers: an outer capsular region composed mostly of connective tissue fibers, and an inner capsular region which contained dense irregular connective tissue, reticular cells and smooth muscle cells. Blood vessels were observed at the interface between the inner and outer capsular regions (Fig. 4). The cortex exhibited two regions: the outer and inner cortex. Whereas, the outer cortex was composed of primary and secondary lymphoid follicles arranged in a circumferential fashion, the deep cortex was an area of diffuse infiltration of small lymphocytes (Fig. 4). The medulla constituted the central part of the haemal node. It exhibited medullary sinusoids and medullary cords. The hilus which was observed at the centre of the nodal tissues contained a lymphatic vessel, blood vessels and sinusoids (Fig. 4). The subcapsular, trabeculae, cortical and medullary sinusoids contained elements of circulating blood.

\section{Histology of WAD goat haemal node}

The haemal nodes of West African Dwarf (WAD) goats are small encapsulated organs that contained

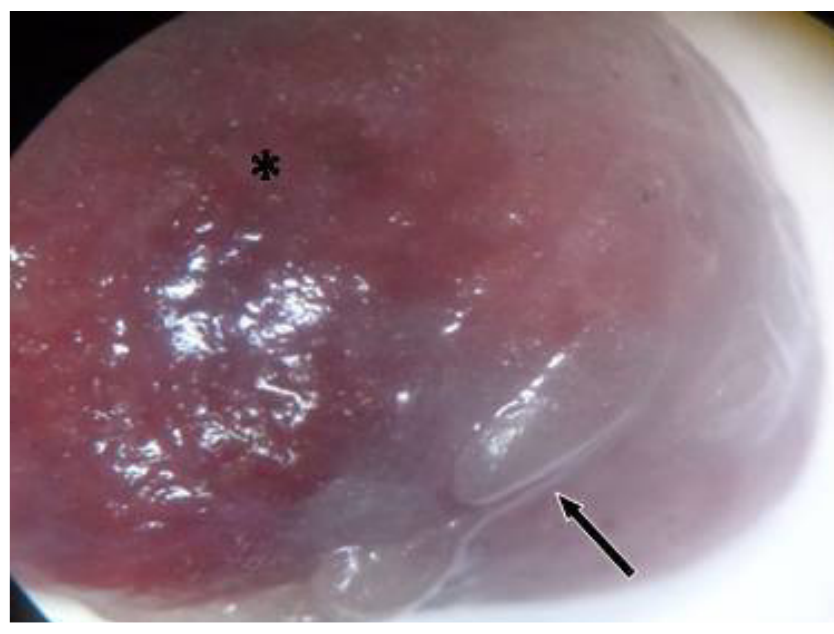

Fig. 3. The photograph of pig haemal node showing a thin transparent and glittering capsule (asterisk) with a longitudinal groove (arrow). Stereomicroscope: $\mathrm{x} 2$ 
morphologically distinct subcapsular, cortical and medullary regions (Fig 5A). The thin connective tissue capsule was composed of a dense irregular connective tissue, reticular cells and smooth muscle cells. The reticular cells and smooth muscle cells of the capsule were oriented in different directions (Fig. 5B). Whereas the capsule contained a circumferential lymphatic vessel, radial lymphatic vessels were observed within the trabeculae together with blood vessels (Fig 5C). The parenchyma of WAD goat haemal node was histologically divided into a distinct cortex and medulla. The cortex exhibited an outer region and a deep cortical region. In the outer cortical parenchyma, randomly distributed primary lymphoid follicles and secondary lymphoid follicles were observed. These lymphoid follicles were either partially or completely surrounded by blood sinusoids. The medulla of WAD goat haemal nodes consisted of medullary sinusoids and medullary cords. These sinusoids were extensive and had boundaries with the intervening medullary cords. WAD goat haemal nodes exhibited subcapsular, trabeculae, cortical and medullary sinusoids that contained abundant pockets of erythrocytes, isolated lymphocytes and macrophages (Fig. 5D). The haemal nodes of WAD goats showed a single hilum which contained an artery.

\section{Discussion}

The results of the present study revealed the presence of haemal nodes in the pig. These nodes were distributed in the thoracic, abdominal and pelvic regions along the course of blood vessels, near lymph nodes. The presence of haemal nodes along the blood vessels suggests that they are sites for immune surveillance of the blood stream (Ezeasor and Singh, 1988; Cerrutti and Guerrero, 2001; Ozaydin et al., 2012), while their occurrence near lymph nodes may suggest that haemal nodes have similar embryonic origin and development as lymph nodes (Sabin, 1905; Okpe, 2001;

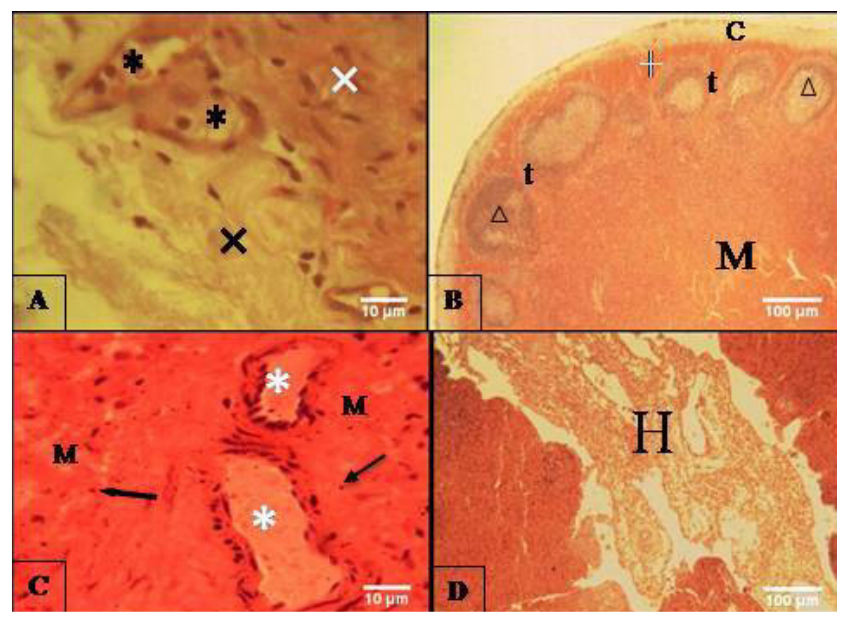

Fig. 4. Photomicrographs of cattle haemal node (A, B, C, D) showing outer (black star) and inner (white star) capsular regions, subcapsular sinusoid (+), circumferential arrangement of lymphoid follicles (small triangles) in the cortex, trabecular sinusoid $(\mathrm{t})$, medullary sinusoid $(\mathrm{M})$, arterioles (black asterisks) and venules (white asterisks). $\mathrm{H} \& \mathrm{E}$ stain: $\mathrm{A}=\mathrm{x} 400 ; \mathrm{B}=\mathrm{x} 40$; $\mathrm{C}=\mathrm{x} 400 ; \mathrm{D}=\mathrm{x} 40$
Vondenhoff et al., 2009; Choudhary et al., 2011). The lymph sacs that formed the lymph nodes and haemal nodes may have developed side by side, but the sacs which formed the haemal node may have lost its lymph vessels during development. These sacs could then become surrounded by aggregations of lymphoid tissues and the mesenchymal cells that surround the lymph sacs may infiltrate the structures, giving rise to a network of blood channels (Sabin, 1905). The anatomical locations of haemal nodes of pigs are comparable to the locations of haemal nodes in WAD goat (Okpe, 2001) and cattle (Bassan et al., 1999; Casteleyn et al., 2008).

The pink, brown and dark brown colours of haemal nodes observed in the present study probably reflect its histologic content of erythrocytes. Several reports on the haemal nodes have shown that the sinusoids of haemal nodes contain pool of red blood cells. These observations correspond to earlier reports in caprine (Ezeasor and Singh, 1988; Choudhary et al., 2011), cattle (Cerrutti and Guerrero, 2001; Casteleyn et al., 2008) and dromedary camel (Zidan and Pabst, 2004). Our study further showed that haemal nodes varied greatly in size. The range of the longest diameters of haemal nodes were $6.1-30.3 \mathrm{~mm}$ in pig, $4.1-18.7 \mathrm{~mm}$ in cattle, and $2.7 \mathrm{~mm}-8.2 \mathrm{~mm}$ in WAD goat. Ezeasor and Singh (1988) reported a size range of $1-5 \mathrm{~mm}$ for the haemal nodes of WAD goat, while Choudhary et al. (2011) reported 5-6 mm for the haemal nodes of goat. In cattle, the range of the longest diameter of haemal nodes as reported by Casteleyn et al. (2008) was 1- $9 \mathrm{~mm}$. The current study showed that the longest diameters of cattle and WAD goat haemal nodes approximately corresponded to the values reported for the same species in previous studies, but varied in the upper limit values of the

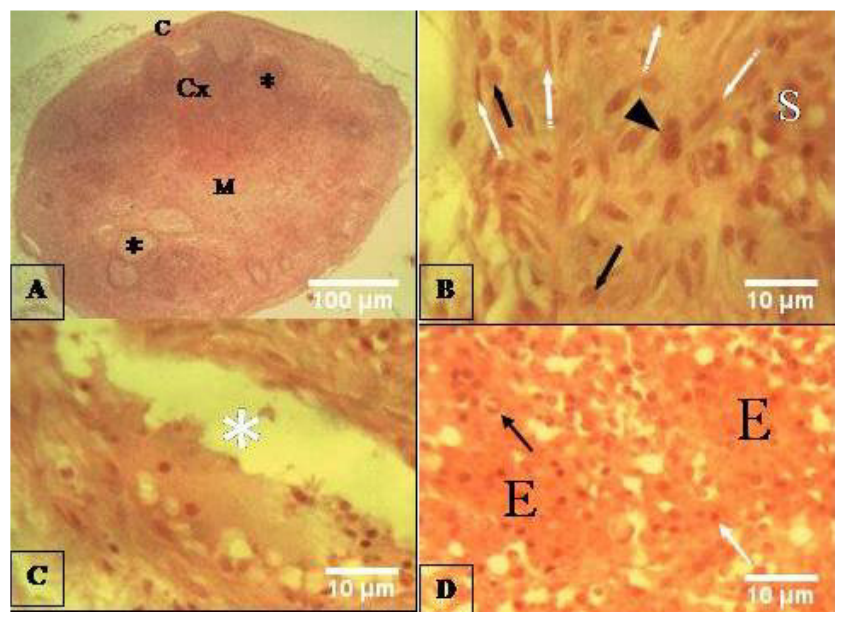

Fig. 5. Light micrographs of WAD goat haemal node (A, B, C, D) showing the capsule (C) exhibiting randomly arranged smooth muscle (white arrows) and reticular (black arrows) cells, macrophages (arrow head) and lymphatics (white asterisks). Note the randomly arranged lymphoid follicles (black asterisks) in the cortex and the pockets of erythrocytes (E) in the medulla. $\mathrm{H} \& \mathrm{E}$ stain: $\mathrm{A}=\mathrm{x} 40 ; \mathrm{B}, \mathrm{C}, \mathrm{D}=\mathrm{x} 400$ 
426

longest diameters. These observations indicate that the size of haemal nodes may vary considerably within and across species.

In the present study the reticular and smooth muscle cells distribution in the capsules of cattle and WAD goat haemal nodes may be responsible for the concentration of red blood cells within the sinusoids because of their contractile ability. The random orientation of reticular cells and smooth muscle cells within the capsule of WAD goat haemal nodes, as illustrated in the present study, suggest that these cells contract in several directions and are most probably responsible for the concentration of red blood cells in pockets within the sinusoids of WAD goat haemal nodes. This later observation is at variance with the reports of previous authors on the haemal nodes of WAD goats (Ezeasor and Singh, 1988; Akaydin and Kabak, 2010). Moreover, this unique feature of random orientation of reticular cells, smooth muscle cells in the capsule, as well as the pocket distribution of erythrocytes in the sinusoids of WAD goat, may aid the identification of the haemal nodes of WAD goats. Furthermore, the clearly defined cortex and medulla exhibited peculiar features which were characteristics of the species. For instance in the cortex of WAD goat haemal nodes, the primary and secondary lymphoid follicles were randomly distributed in the cortex while they were distributed in a circumferential fashion in the cattle haemal nodes. The circumferential distribution of lymphoid follicles was consistent in all studied haemal nodes of cattle. Moreover, the population of lymphoid follicles found in the cattle and WAD goat haemal nodes may be dependent on antigen stimulation (McLennan, 1994; Naito et al., 2007; Klein and Dalla-Favera, 2008).

In the sinusoids of the haemal nodes of cattle and WAD goat reported in the present study, erythrocytes were densely concentrated, suggesting a microenvironment that is devoid of oxygen, a condition necessary for blood storage (Zimrin and Hess, 2009; Yoshida and Shevkoplyas, 2010). This observation corresponds to the reports of several previous authors on the presence of erythrocytes in the haemal node sinusoids (Ezeasor and Singh, 1990; Zidan and Pabst, 2004; Ozaydin et al., 2012; Zidan and Pabst, 2012). However, the pocket distribution of erythrocyte in the WAD goat haemal node is peculiar to this study. Furthermore, macrophages, which lined the sinusoids, could perform phagocytic functions. In addition, these macrophages may process and present antigens to immune competent $\mathrm{T}$-cells (Abbas et al., 2007).

Most researchers believed that during development, the lymph sacs which formed haemal nodes may have lost their lymph vessels (Sabin, 1905). However, it is obvious in the present study that lymph vessels may not have been completely lost at development. Although there was no evidence of afferent lymphatic vessels in WAD goat and cattle haemal nodes, the present study demonstrated efferent lymphatic vessels in the haemal nodes of WAD goat and cattle. This view is confirmed by the opinion of some previous authors (Ezeasor and Singh, 1990; Bassan et al., 1999; Choudhary et al., 2011), but it is at variance with the reports of Thorp et al. (1991), Dassanayake et al. (2005), Casteleyn et al. (2008) and Ozaydin et al. (2012).

\section{Conclusions}

The present study has provided vivid evidences on the occurrence and distribution of haemal nodes in pigs as well as unique morphological peculiarities of pig, cattle and WAD goat haemal nodes, highlighting the structural differences and functional significance of haemal nodes in the studied species. It promotes the idea that haemal nodes may have similar embryonic origin as lymph nodes, and may vary in size and in structural features within and across species.

\section{References}

Abbas AK, Lichtman AH, Pillai S (2007). Antigen processing and presentation to $\mathrm{T}$ Lymphocytes. Cellular and molecular immunology 6th ed. Pensylvania: Saunders.

Akaydin B, Kabak M (2010). Morphology of haemal nodes in the roe deer (Capreolus capreolus). Anatomia Histologia Embryologia 39:456-461.

Bacha WJ, Bacha LM (2000). Color atlas of veterinary histology, 2nd ed. London: Lippincott Williams and Wilkins.

Bassan N, Vasquez F, Vinuesa M, Cerrutti P, Bernardi S (1999). Morphological alterations in hemal nodes in splenectomized cattle. Arquivo Brasileiro de Medicina Veterinária Zootecnia 51:16.

Casteleyn CR, Breugelmans S, Simeons P, Van den Broeck W (2008). Morphological and immunological characteristics of the bovine temporal lymph node and haemal node. Veterinary Immunology and Immunopathology 126:339-350.

Cerutti P, Guerrero F (2001). Identification of positive cells to interleukin- 4 in bovine haemal nodes. Anatomia Histologia Embryologia 30:219-223.

Cerutti P, Guerrero F (2008). Erythropoiesis and erythrophagocytosis in bovine haemal nodes. International Journal of Morphology 26:557-562.

Choudhary RK, Das P, Ghosh RK (2011). Post natal development of caprine haemal nodes: a gross and histological study. Journal of Cell and Tissue Research 11:2919-2923.

Dassanayake RP, Truscott TC, Ozyirit MO, Zhuang D, Schneider DA, O'Rourke KI (2013). Accumulation profiles of PrPSc in hemal nodes of naturally and experimentally scrapie-infected sheep. BMC Veterinary Research 9:82.

Ezeasor D, Singh A, Sims DE (1989). Erythrophagocytosis in the caprine haemal nodes. Acta Anatomica (Basel) 134:341-345.

Ezeasor DN, Singh A (1988). Histology of the caprine haemal node. Acta Anatomica (Basel) 133:16-23.

Ezeasor DN, Singh A (1990). Morphologic features of lymph vessels in caprine Heamal nodes. American Journal of Veterinary Research 51:1139-1143.

Klein U, Dalla-Favera R (2008). Germinal centres: role in Bcell physiology and malignancy. Nature Reviews Immunology 8:2233.

McLennan ICM (1994). Germinal centres. Annual Reviews Immunology 12:117-139.

Naito Y, Takematsu H, Koyama S, Miyake S, Yamamoto H, 
Fujunawa R, et al. (2007). Germinal centre marker GL7 probes activation-dependent regression of N-Glycolyneuraminic acid, a Sialic acid species involved in the negative modulation of $\mathrm{B}$ cell activation. Molecular and Cell Biology 27:3008-3022.

Okpe GC (2001). Distribution pattern of haemal nodes in West African Dwarf Goats. Global Journal of Pure Applied Sciences 7:241-243.

Ozaydin T, Sur E, Celik I, Oznurlu Y, Aydin M (2012). Histological and enzyme histochemical investigation of the haemal nodes of the hair goat. Biotechnic \& Histochemistry 87:377-384.

Sabin FR (1905). The lymphatic system in human embryos, with a consideration of the morphology of the system as a whole. American Journal of Anatomy 9:43-91.

Thorp BH, Seneque S, Staute K, Kimpton WG (1991). Characterization and distribution of lymphocyte subsets in sheep hemal nodes. Developmental \& Comparative Immunology 15:393-400.

Udoumoh AF, Ezeasor DN (2015). Developmental features of porcine haemal nodes: a histological perspective. Animal Research International 12:2241-2248.

Vondenhoff MF, van de Pavert SA, Dillard ME, Greuter M, Goverse
G, Oliver G, Mebius RE (2009). Lymph sacs are not required for the initiation of lymph node formation. Development 136:29-34.

Winqvist G (1954). The bovine haemal nodes. Acta Anatomica 22:108-112.

Yoshida T, Shevkoplyas SS (2010). Anaerobic storage of red blood cells. Blood Transfusion 8:220-236.

Zidan M, Pabst R (2004). Histological, histochemical and immunohistochemical study of the hemal nodes of the dromedary camel. Anatomia Histologia Embryologia 33:284289.

Zidan M, Pabst R (2012). Histological, histochemical and immunohistochemical study of the lymph nodes of one humped Camel (Camelus dromedaries). Veterinary Immunology and Immunopathology 145:191-201.

Zimrin AB, Hess JR (2009). Current issues relating to the transfusion of stored red blood cells. Vox Sanguinis 96:93-103. 